\title{
Feedback on Feedback: Preservice ESL Teachers Respond to Evaluation Practices
}

\author{
Sandra G. Kouritzin and Carol Vizard
}

Although a number of studies have examined the role of teacher feedback in ESL students' learning, equal attention has not been paid to how ESL teachers make feedback decisions based on their preservice preparation. In this article, preservice ESL teachers respond to various forms of feedback that they received in their TESL Methodology course, and offer insights into how these individual responses will shape their own evolving feedback practices. Quoting from students' journal entries and audiotaped group discussions, this action research project reveals that preservice ESL teachers were pleased with the wide variety of feedback formats and sources used in this course and that they intended to replicate this variety in their own classrooms. In general, this small group of preservice ESL teachers liked feedback that was immediate, detailed, ungraded yet critical, and focused. They preferred feedback to come from credible and authoritative sources.

Recently, a number of studies of the kinds of feedback ESL students receive, and how that feedback may be incorporated into their learning, have appeared (Boswood \& Dwyer, 1995/6; Hedgcock \& Lefkowitz, 1994; Hyland, 1990; Connor-Linton, 1995; Ferris, 1995; 1997; Leki, 1991; Robb, Ross, \& Shortreed, 1986; Saito, 1994). Noted for its absence, however, is commentary on the kinds of feedback preservice ESL teachers (PSESLTs) receive during their educational experiences and the resulting influences on the forms of feedback they give as TESL professionals.

With this in mind, the purpose of the study reported here is to explore PSESLTs' reactions to various forms of in- and out-of-classroom feedback in an action research project and to discuss how their experiences with different forms of evaluation shape PSESLTs' thoughts vis-à-vis the types of classroom feedback they intend to give (and to seek) in their own teaching. This goal necessitates detailing what is meant by feedback and evaluation and how these fit into the general field of assessment.

\section{What is Feedback?}

Most often, studies of feedback equate it with assessment, making a distinction between formative (i.e., process-oriented) and summative (i.e., productoriented) assessment. The former is used to assist students in revision of completed work, and the latter is used to grade students. Particularly in adult teaching contexts, this distinction is problematic. First, all summative evaluation is also formative evaluation in that knowledge (of language, of 
subject matter, of teaching, or other arts) is considered to be cumulative. Second, in many adult educational contexts, summative evaluation does not exist. ${ }^{1}$ Students are seldom graded, although they might be streamed by institutional or noninstitutional tests.

We therefore find it more helpful to think of assessment as being divided into testing and measurement and feedback. Testing and measurement, the politics of which have become a hotly contested field of debate in TESL (Spolsky, 1995; Bachman, 1991; Shohamy, 1993), serves a gatekeeping and accountability function, assigning numbers and grades to students in order for them to be included in, or excluded from, a cohort. Those taking the tests are not often told the reasons why they were assigned a particular grade, nor do they have the opportunity to review their answers in order to learn from their successes and mistakes. Feedback (our focus here), on the other hand, is continuous, ongoing, and interactive; it comes not only from teachers, but also from peers, parents, friends, and, in the case of preservice teachers, students in their practicum classrooms. Feedback assumes the form of grades, comments, error-correction, peer review, body language, facial expression, consultation, conversation, or self-evaluation, and it may be written (Ferris, 1995, 1997), spoken (e.g., peer or teacher conferences), audiotaped (Hyland, 1990; Boswood \& Dwyer, 1995), videotaped (for self-evaluation), norm-referenced or criterion-referenced (e.g., standardized tests), marginnoted and/or end-noted (Ferris, 1995, 1997), directive or nonspecific (Robb et al., 1986; Hyland, 1990), or student-generated (Charles, 1990).

\section{The Sources of Feedback for PSESLTs}

Feedback not only comes from a variety of sources and in a variety of forms, but it is also influenced by the contexts in which it is given or received. The way PSESLTs perceive feedback is influenced by previous experiences at home and at school, from family and friends, from teachers and peers (see Figure 1). On beginning teacher training, PSESLTs' personal theories of feedback are then influenced by (a) educational theory from their texts and their classes, (b) personal and vicarious experiences in their TESL training program, and (c) observation of their practicum classrooms and other classrooms to which they have access. Their developing theoretical, experiential, and observational knowledge creates a continually changing context with which PSESLTs continue to judge theory, experience, and observation. During their practice teaching and teaching practice, PSESLTs gauge how their students react to feedback and how they progress in response to different feedback types, eventually developing a personal feedback style. Although through trial and error they do develop individual practices of oral, written, physical, and affective feedback, they are often unable to articulate why their feedback practices have evolved, and on what bases they have made feedback decisions. 


\section{Studies of Feedback}

Most feedback studies in TESL have focused on either ongoing teacher development (i.e., the evaluation of inservice teachers by principals or administrators, Machell, 1995; Sweeney, 1992), or on process writing (i.e., the feedback given to ESL students [not PSESLTs] by peers and teachers on early drafts of papers that they are expected to revise Charles, 1990; Hyland, 1990; Robb et al., 1986, Boswood \& Dwyer, 1995/6; Ferris, 1995; 1997; Saito, 1994). Although the first class of studies notes a "lack of training among participants in effective evaluation and feedback procedures" (Machell, 1995, p. $262)$, the second begins with the assumption that students will revise and resubmit their written work, not always a valid assumption. This study, by contrast, aims to keep in mind Stiggins' (1991) admonition that,

With respect to the other forms of feedback teachers use, such as oral communication, nonverbal communication, written comments, teachers carry out sound practices when they focus feedback on clear expectations, time feedback to ensure student attention, and check for understanding of feedback. Teachers need to learn these things somewhere in their professional preparation. (p. 10)

\section{Design of the Action Research Project}

The course, Teaching English as a Second Language Methodology (adult), was an undergraduate course with a practicum component required for the diploma or certificate in TESL, in a large university in a linguistically diverse urban setting. PSESLTs in the class were primarily native speakers of English; however, three PSESLTs spoke Russian as a first language, one Japanese, and one Korean. Two of the students were practicing ESL teachers (including Vizard), one had TESL, and two others had TEFL experience.

During the fall and winter terms of 1997-1998, the course instructor ${ }^{2}$ gave the following assignments, here itemized in chronological order:

1. Micro-teaching (four short lesson plans "taught" in small groups);

2. Unit plan (content, task, or project based);

3. Course Journal;

4. Book Review (evaluation of ESL teaching textbook or resource book);

5. Formal written paper (on some aspect of a social issue in TESL).

The course instructor also arranged $20+$ hour practica for the students and observed their teaching.

During an early discussion about assessment in TESL, PSESLTs and the instructor decided to engage in an action research project in which the PSESLTs would assess the various forms of feedback that they received in the course. Therefore, each course assignments was evaluated in a different manner as suggested by the instructor and approved by the PSESLTs. 


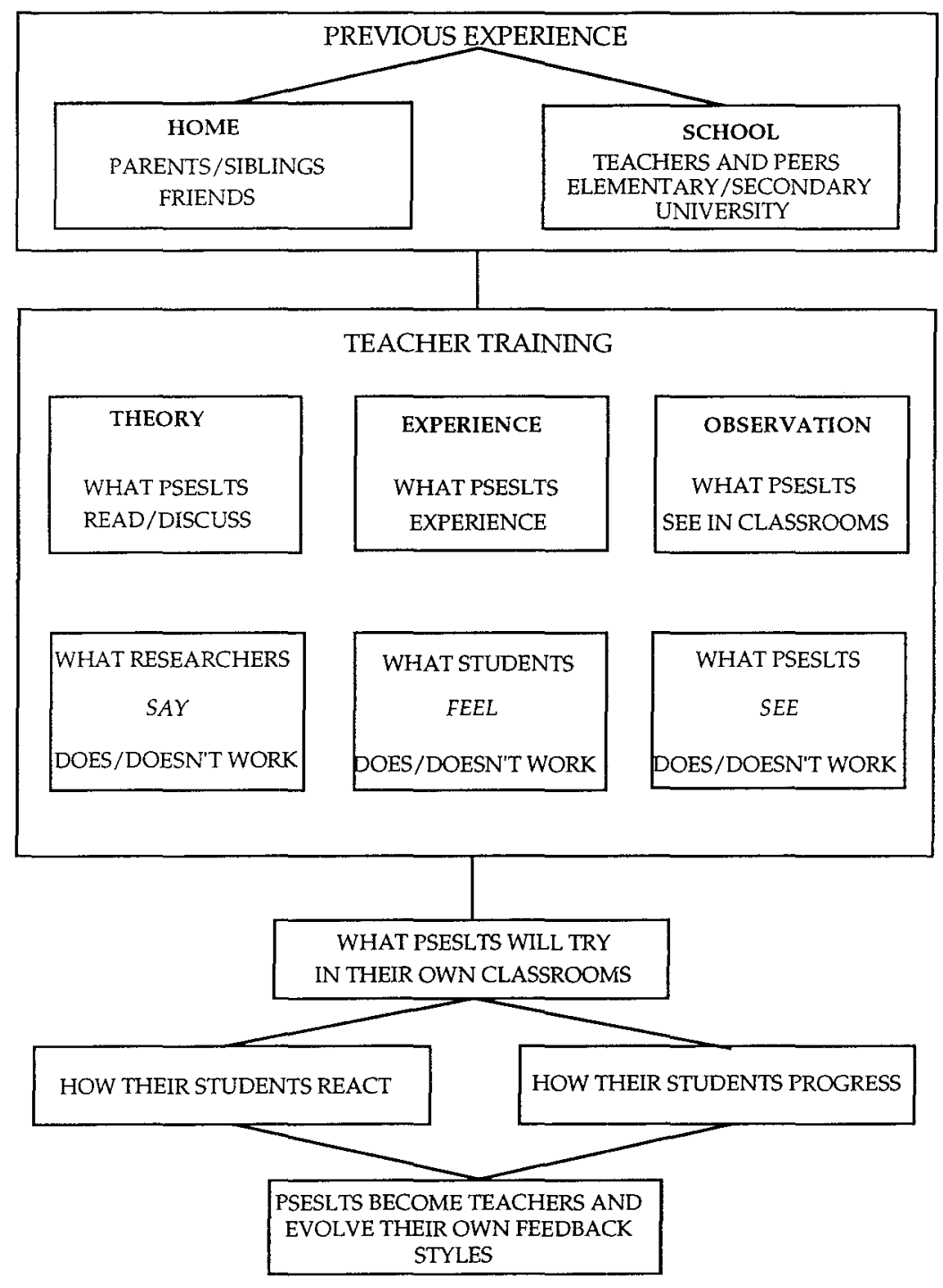

Figure 1. Sources of evolving feedback.

The micro-teaching was evaluated by (a) small micro-teaching groups with peers giving feedback or suggestions on the lesson plan and its execution, (b) letters written by the instructor addressing potential problems and/or extensions for the various tasks, (c) self-analysis from videotapes of the sessions, and (d) reflection in course journals about the feedback each 
PSESLT received and how it was incorporated into the design of the unit plan. $^{3}$

The unit plans were evaluated by the instructor. PSESLTs were allowed to work alone or with partners, and were asked to submit a blank 60 -minute cassette tape with the unit plan. While reading the unit plans, the instructor audiotaped ongoing feedback, quoting from the unit plans so that the PSESLTs could follow. This feedback stressed extensions for the tasks, possibilities, ideas, comments about form, and the personal experiences of the instructor when teaching similar lessons. At the end of the tape, the instructor then summarized and assigned a grade by individually addressing each item on a list of criteria outlined in the course syllabus. ${ }^{4}$

The journal, handed in at the end of the course, was annotated anecdotally, and graded pass or fail, judged only on the basis of whether it was completed, so that the instructor could not unconsciously give higher grades to those students who reflected her own views.

The book review had two components: (a) a one-page written review of the text or resource book's usefulness, cultural content, learning principles, motivational prompts, appropriateness, methodologies, and organization; and (b) a 5-minute oral presentation. It was evaluated using a Li\&kert-scale checklist based on criteria outlined in the syllabus assessing both the oral presentation and the written review.

The formal, written "social issues" paper was evaluated using margin notes and end notes written onto the assignments by the instructor. When writing margin notes, the instructor focused particularly on making personal comments such as "I have always been interested in this myself," or on giving students directive feedback such as "You may be well advised to consult the APA for standard referencing procedures." Sometimes the margin notes were lengthy and anecdotal, making reference to classroom discussions or to shared experiences. The end notes, by contrast, were summative, making reference to the criteria outlined in the syllabus.

During the practicum (which was marked on a pass-fail basis, a pass being required for successful completion of the course), PSESLTs were evaluated in an ongoing manner by the sponsor teacher (a practicing teacher in a recognized ESL institution), and then formally both by the practicum supervisor and by the sponsor teacher on a standardized form prepared by the university department. On completion of the practicum, each PSESLT had an hour-long conversational, two-way feedback meeting with the practicum supervisor.

\section{Data Collection and Analysis}

During the first term of the course, with approval of the research ethics committee at the university, the instructor (Kouritzin) asked if any PSESLTs were interested in co-authoring a paper (Vizard volunteered) and if any 
PSESLTs would object to formalizing this research project. All PSESLTs were eager to engage in this study, and it was agreed that they would comment in their journals about (a) the strengths and weaknesses of the various forms of feedback, and (b) what effect this had or would have on their classroom choices. As a group, we listed not only the types of feedback provided by the instructor, but also visual, auditory, and affective feedback given by family, friends, students, and sponsor teachers so that all PSESLTs would have the same point of departure for their journal entries (summarized in Figure 2). It was agreed that the instructor also share her experiences of giving the various forms of feedback. Two class discussions were chaired, audiotaped, and analyzed by Vizard.

When the journals were submitted, they were photocopied without names and each journal was given a number from 1 to $15 .{ }^{6}$ To further ensure anonymity, we made efforts to conceal whether each journal was written by
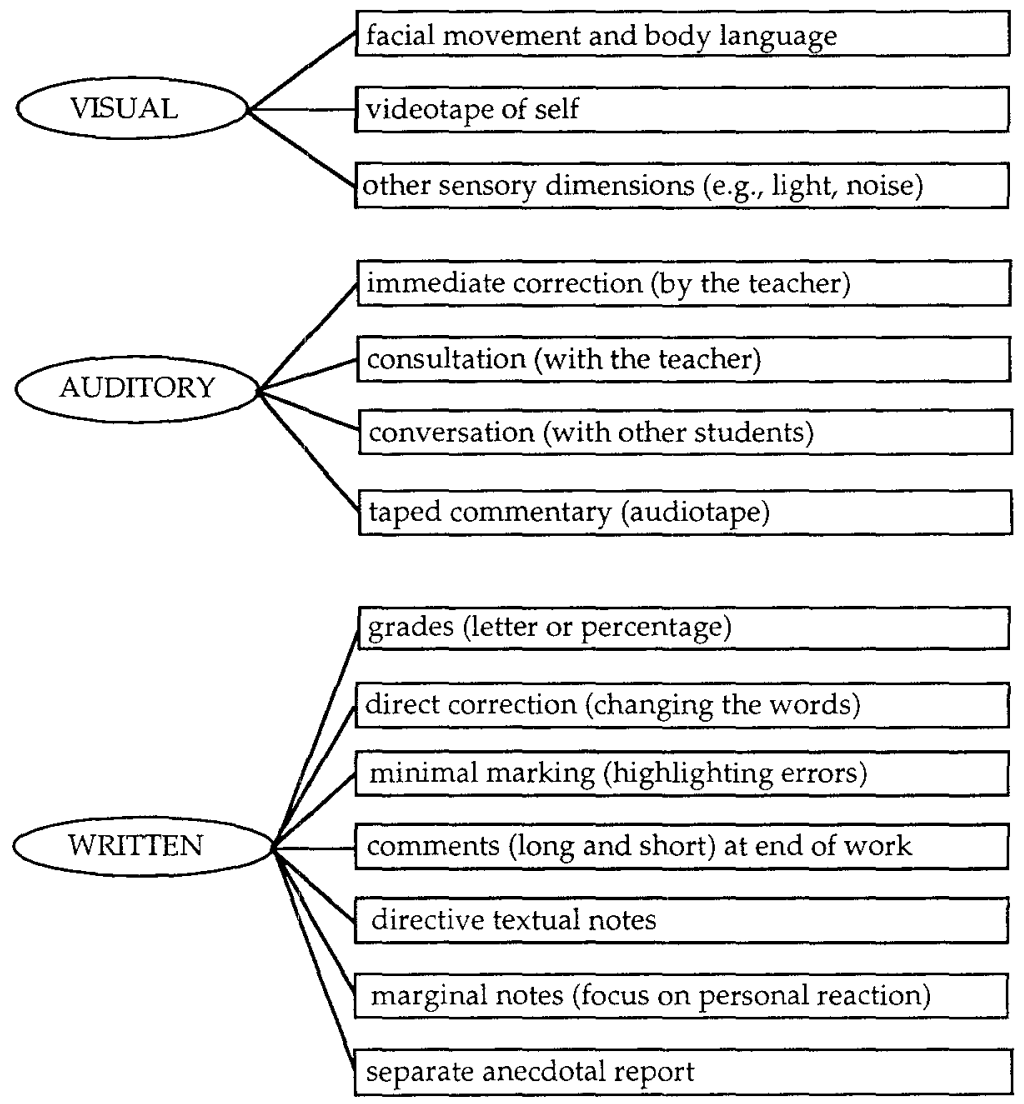

Figure 2: Student-suggested forms of feedback from class discussion. 
a man or woman, and whether the writers were native or nonnative English speakers.

The journal entries and transcripts were read individually by both authors. First, categories were established that seemed to cover all the forms of feedback that were used in the course. Although the instructor had referred to Figure 2 when planning and suggesting feedback formats for each assignment, these categories were inadequate to the data. For example, comments on body language or other forms of visual feedback were made only in reference to particular sources (the sponsor teacher or practicum students), and some feedback (such as that from family and friends) had not been discussed in class although it appeared in the journals, whereas some categories discussed in class (e.g., previous feedback experiences) did not appear in the journals. The categories that emerged in the PSESLTs' journals are shown in Table 1.

Table 1

Comments Given by PSESLTs About Sources and Forms of Feedback

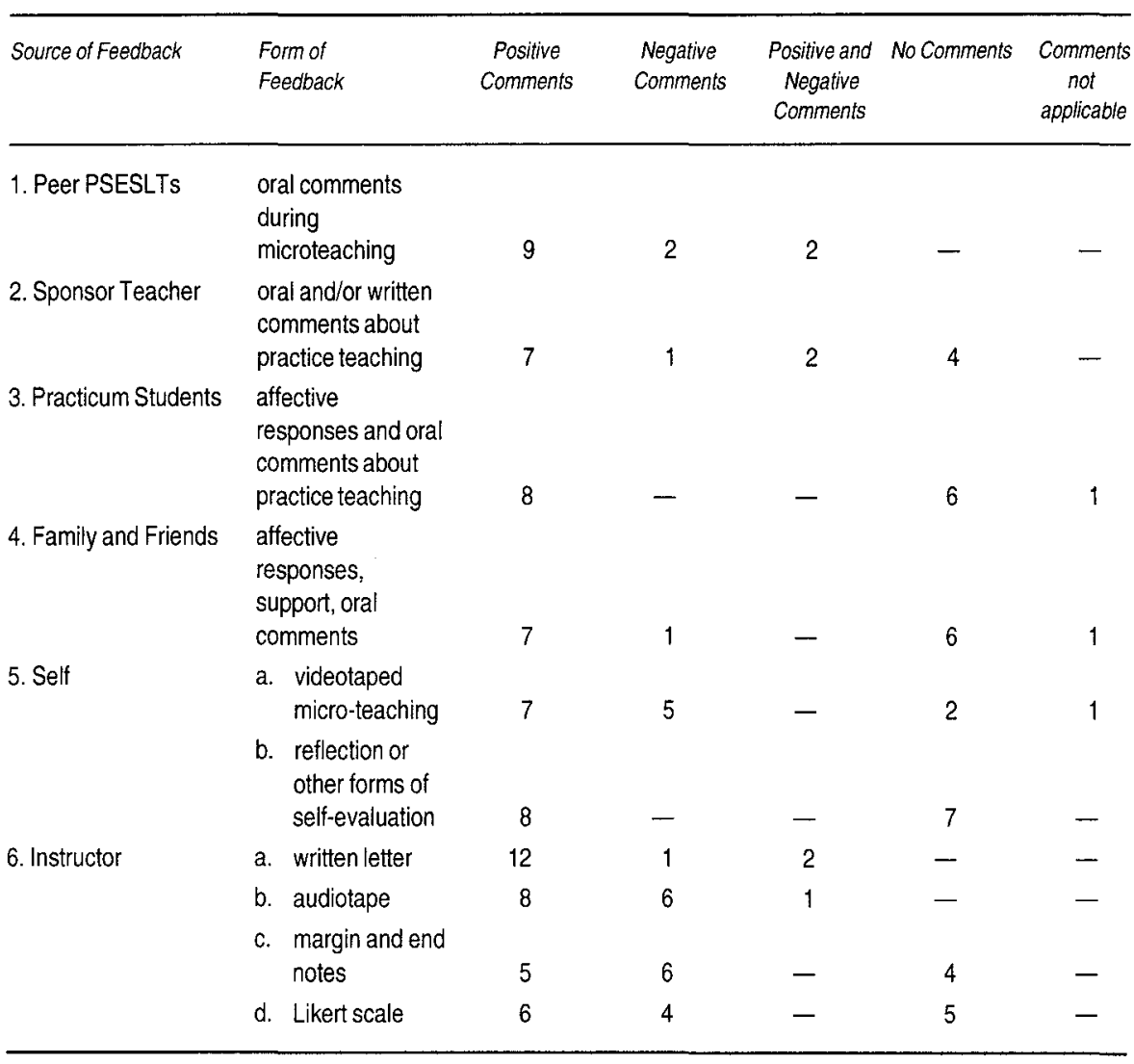


Next, in each category the entries were judged to provide (a) positive comments, (b) negative comments, (c) positive and negative comments, (d) no comment, or (e) comments that were not applicable to the study (see Table 1). Any differences in researcher opinion were discussed and resolved. Positive and negative reactions are summarized in the section below (Findings). Finally, representative positive and negative quotations were extracted from the journals about each of the various forms of feedback (see below, PSESLTs' Comments) in order to aid our understanding of why certain forms of feedback were perceived to be more effective than others.

\section{Findings: The Effectiveness of Forms of Feedback}

For ease and coherence of presentation, we have categorized the forms of feedback according to their sources and numbered them as in Table 1.

1. Reflections on peer feedback following micro-teaching sessions were recorded by 13 PSESLTs ( 9 positive, 2 negative, and 2 positive and negative). As these micro-teaching sessions took place early in the school year, many PSESLTs felt highly vulnerable during these first attempts at "teaching" a class-here to their peers-which may have contributed to their appreciation of the primarily positive feedback given by their classmates. PSESLTs with classroom experience were more critical of peer feedback, finding it lacking in critical acuteness. Two PSESLTs did not comment on this type of feedback.?

2. Seven out of the 10 PSESLTs who responded in their journals to the feedback given by their sponsor teachers felt that it was highly valuable, especially as it was immediate, concrete, and included constructive criticism. Only one PSESLT gave a solely negative response to her sponsor teacher's feedback (see below), but other negative responses were balanced with positive comments. Many PSESLTs did not comment on their sponsor teachers' feedback. Perhaps the PSESLTs did not have the confidence or authority to question their sponsor teachers' feedback. Or, given that they had passed their practica, they did not want to mention poor feedback, fearing it might be reflected in their grades.

3. Those PSESLTS who commented on the feedback they received from their practicum students ( 8 of 15 ) felt positively about it. Yet nearly half of the PSESLTs did not comment on the feedback from their practicum students, even though we had many PSESLT-generated discussions about this kind of feedback in class. Our speculation on the failure to respond ran in two directions. First, we felt that perhaps the PSESLTs did not yet feel comfortable with their own ability to understand their students' indirect feedback. The PSESLTs might have been looking for more traditional forms of input such as students saying "You're doing a wonderful job" (which experienced teachers know is rare) rather than focusing on nonspecific or nonverbal feedback. This point was specifi- 
cally illustrated by two PSESLTs who reported that their practicum students had said nothing to them directly, yet who went on to describe how their students had been friendly and cooperative. Certainly this is feedback-positive feedback —even if the PSESLTs did not recognize it as such. ${ }^{8}$ Second, when they turned in their journals, the PSESLTs had already passed the practicum, and they may have feared discussing negative student feedback in case it influenced their final grade.

4. Only eight PSESLT's commented on the feedback they received from family and friends. Although a number of PSESLTs were single and/or had recently arrived in the city, this does not fully explain why so many PSESLTs failed to comment on outside feedback. We felt that perhaps discussing the feedback of family and friends was considered too personal or irrelevant by many PSESLTs. Alternatively, perhaps PSESLTs did not have the language, facility, or distancing required to relate this information in a concise way.

5a. Reaction to the videotapes of micro-teaching sessions ( 7 positive, 5 negative) was divided, meaning that no PSESLTs expressed ambivalence. Due to difficulties with video cameras, several PSESLTs in the class were unable to watch themselves on video, accounting for those students who did not comment.

5b. Only eight PSESLTs commented on self-evaluation (all positively), and seven failed to comment. There seemed to be some kind of confusion on the part of the PSESLTs as to what constituted self-evaluation, whether it was a separate formal form of assessment, whether it meant watching themselves on the videotapes of the micro-teaching sessions, or whether it meant reflection after practice teaching.

6a. Most of the PSESLTs (12 of the 15) responded positively to the written feedback in the letter given by their instructor for micro-teaching lesson plans. This written feedback received either negative or positive (or a combination of both) commentary from all of the PSESLTs. They had never received this type of feedback before the course, and they responded to its novelty.

$6 \mathrm{~b}$. Comments on the audiotaped response to unit plans ( 8 positive, 6 negative), like the comments on the videotaped micro-teaching sessions, was divided and not ambivalent. As was the case with the written letter feedback, none of the students in this course had ever received this type of feedback in the past, and they had strong reactions to it.

$6 c$, Margin and end notes on formal academic assignments (5 positive, 6 $6 \mathrm{~d}$.negative) and Lickert-scaled evaluation (6 positive, 4 negative) also received split responses. Of particular interest is that during discussions led by Vizard, PSESLTs explained that they accepted the authority of these forms of feedback because they were most familiar with them. In 
the discussion and in their journals, most PSESLTs commented that these forms lacked attention to detail and structure.

Finally, only one PSESLT accepted the invitation to discuss feedback received in prior formal educational experiences (as in Figure 1) and to trace how current responses to the various forms of feedback may have been influenced by past experiences; therefore, we chose to omit discussion of this category. Perhaps PSESLTs did not feel equipped to attempt this kind of reflection, or perhaps they just wanted to finish the assignment and finish the course.

As this is a small group of PSESLTs, findings, of course, cannot be conclusive. All the feedback given by the PSESLTs was subjective; they chose not to rank the different forms, or to list the pros and cons, but rather just to reflect on and write feedback on feedback. How each form of feedback was received could be affected by many factors including, but not limited to, self-esteem, the ability to accept criticism, whether the feedback was recent or long past, the PSESLT's relationship with or respect for the evaluators, or the PSESLTs' perceptions of their hierarchical placements in the class.

\section{PSESLTs' Comments on Forms and Sources of Feedback}

\section{Peer feedback during micro-teaching sessions}

Peer feedback tied with self-evaluation for the second most highly rated form of feedback. In light of Belanger and Sloan's (1995) finding that students interpret feedback according to the grade they receive, this is particularly interesting; the three most highly regarded forms of assessment were those in which the PSESLTs did not receive a grade at all. On the other hand, the strength of this method may be due to the amount of time we spent as a class discussing the various forms that peer feedback could take. We referred to feedback that was directed only to the positive aspects of each PSESLT's micro-teaching performance and compared this with the kind of feedback we were all familiar with-feedback that opened with a positive statement, then itemized everything wrong, and closed with a positive statement. We talked about how to make charts of strengths and weaknesses and decided that things to consider was a nicer way of phrasing weaknesses. Some PSESLTs felt that they did not want to know what they had done well because they wanted to concentrate on what "needed fixing," whereas others wanted every positive comment balanced by a negative one and vice versa. We agreed as a class that each group could make decisions about what kind of feedback was warranted and whether the feedback would be given orally or in written form. None of the PSESLT journals commented on our preparation for peer feedback, but I (Kouritzin) would be hesitant to introduce it into a classroom without adequate preparation.

What the PSESLTs liked about peer feedback was immediacy, applicability, and egalitarianism. They felt that because the feedback was given 
as soon as the micro-teaching lesson was complete, they were able to draw detailed feedback about everything from their speaking habits to their use of visual aids. PSESLTs commented that receiving peer feedback was applicable because it "enabled me to realize what would be my potential problem in actual teaching sessions throughout the practicum" (Journal \#13) and that giving peer feedback was applicable because "it was really valuable to learn how to give feedback to another in a constructive way" (Journal \#12). Finally, they enjoyed the egalitarianism of peer feedback because of "the comfort of realizing that each member of the group was in a learning position, and so criticism of points in a lesson were constructive and in no way threatening on a personal level" (Journal \#4). On the other hand, several PSESLTs commented that classmate feedback was not so helpful because "peers are often too kind to criticize" (Journal \#8) and it "lack[s] the weight of an instructor's evaluation" (Journal \#9). From the point of view of the instructor, peer feedback was not always "gently padded" (Journal \#4) nor "encouraging and helpful" (Journal \#3). I (Kouritzin) found it surprising that no mention was made in any of the journals about the large number of times I was asked to sit in on particular micro-teaching sessions because a PSESLT was feeling discouraged or victimized by peer response and wanted me to intervene.

\section{Feedback from sponsor teachers}

In the university where this study took place, the practicum is marked on a pass-fail basis, but does not contribute to the course percentage. Although failure to pass the practicum results in a course mark of zero, a weak pass is not differentiated from a strong pass. The practicum experience tends to set the sponsor teacher and PSESLT up as collaborators who together work toward the goal of the PSESLT passing the practicum during a formal instructor observation. Feedback from the sponsor teacher can, therefore, be seen as nonevaluative. As with other nonevaluative feedback, comments from the sponsor teacher were seen as positive (i.e., those who commented tended to do so favorably). PSESLTs enjoyed this kind of feedback, often saying that it was the criticism and the collegiality that they most enjoyed. Two PSESLTs stated this most succinctly:

The nicest thing about her was that she did not hesitate to talk about negative things because she knew exactly why I came here, that is, to improve my teaching. In other words, I was prepared to be criticized. Therefore, we were able to talk about my teaching very frankly. (Journal \#2)

The feedback that I received from my sponsor teacher was very encouraging. However, I feel that she could have given more criticism and suggestions for how to approach the specific class.... The sponsor teach- 
er treated me as an equal and was supportive of any lesson that I wanted to try. (Journal \#3)

These two PSESLTs' comments are representative of the other PSESLTs who also mentioned being prepared for, even looking forward to, criticism from the sponsor teacher, perhaps because they knew that course marks were not attached to this form of feedback.

Unfortunately, PSESLTs and sponsor teachers do not always establish a collegial rapport. Sometimes this is because the PSESLT is unwilling to accept advice, alienates the students, or proves to be a less-than-satisfactory teacher. Other times the reasons are less apparent as proved to be the case with one PSESLT in this class. An experienced K-12 teacher, this PSESLT wrote excellent lesson plans, performed well in micro-teaching, and was highly regarded by the administrator of the institution in which she did her practicum. It was, therefore, unexpected that she would find her practicum experience to be demoralizing because of the feedback she received from her sponsor teacher. This PSESLT shared her experience with other PSESLTs, talking to the class about how she felt, and how she dealt with it. In her journal she wrote:

In the practicum, ironically, any written feedback from the sponsor teacher was fairly positive. It was very performance directed; emphasis on timing, logistics of using the board, etc. It was the body language, and expressions that spoke volumes to me in a very negative way. Detached. Once it was decided that I was not meeting the criteria adequately, I was dismissed, not physically, but emotionally. It is that feeling of being dismissed, and feeling that somehow I was being marginalized by her expectations of me that I will carry with me as a reminder of the fragility and vulnerability of seemingly confident, competent adults. May I always be aware of how my posture, my expression affect perhaps not all, but even some of my students. (Journal \#4)

In this PSESLT's case, it proved to be the course instructor's evaluation that gave her support. I (Kouritzin) elected to observe this PSESLT's teaching before her practicum was complete. It was immediately apparent that the sponsor teacher had little respect for the course I taught, as she challenged my authority and credibility before the observation began. During my observation, I noted that the sponsor teacher, although an excellent instructor, had failed to establish a friendly rapport with the students and that the atmosphere in the classroom changed for the better when the PSESLT took over. After my observation, I told the sponsor teacher that the PSESLT had passed her practicum, a decision with which the sponsor teacher disparagingly disagreed. Having student support, the PSESLT was offered a job at that institution after completing her practicum. 
This experience also illustrates how body language feedback, nonverbal feedback, is perhaps the most important of all. As this PSESLT wrote, her spoken and written evaluations were good; it was the affective feedback that made her feel inadequate. Other PSESLTs did not write about similar experiences in their journals, yet I was called on many times to interpret sponsor teacher behavior for the PSESLTs when, for example, sponsor teachers failed to give positive feedback, reduced PSESLTs' responsibility, whispered to some students while the practicum teacher was teaching, or talked about a PSESLT to other teachers.

\section{Feedback from students in practicum classrooms}

Potentially devastating because "silence from the students is a rather frightening response" (Journal \#11), feedback given by students in the practicum class was generally viewed favorably. Except for one PSESLT who stated that "students would even tell me explicitly that I was a good teacher" (Journal \#3), the PSESLTs relied on body language, student response, facial expressions, and enthusiasm to judge how they were doing. One PSESLT went so far as to say that student response was the "most effective evaluation of my teaching" (Journal \#10).

This kind of feedback was most effective for lesson planning and for letting the PSESLT's know when to change an activity. Practicum student feedback let the PSESLTs know which learning activities were appreciated and which were not: "As a classroom teacher-to-be, I realized that I should observe students' reaction toward activities and notice their preferences because it would be important to plan a better lesson" (Journal \#13). Although the PSESLTs took warmth and enthusiasm to be positive, there was also a tendency on the part of these PSESLTs to mistake positive student feedback for an indication of learning. At this stage of their teaching careers, and as evidenced in their journals, these PSESLTs allowed student reaction to govern rather than merely to influence the decisions they made about lesson planning.

\section{Feedback from family or friends}

I would also like to share with you the incredible degree of support and positive feedback I received from my husband. He constantly reassured me of the inherent aptitude I possess when dealing with people and gave me the confidence to teach every Monday morning. I don't think I could have managed without his ongoing praise. (Journal \#1)

This is typical of the comments we expected to receive (and did receive) about the feedback from family and friends. Even when family and friends were in different fields, the PSESLTs liked the feedback they received because it came from a different perspective and made them look at things a new way. PSESLTs remarked that suggestions from family were "very reas- 
suring and surprisingly blunt" (Journal \#9), perhaps because they did not want the PSESLTs to do poorly or to fail.

However, the sole negative comment about the feedback of family and friends, a point of view that we found surprising but compelling, reasoned, "The faith of those close to me in my ability to succeed, exerted a certain amount of pressure on me and made the possibility of failure unthinkable" (Journal \#11). In fact, this comment made one of the authors (Kouritzin) reflect about her own experiences as a graduate student and realize that it was this kind of pressure that kept driving her to work harder in order to feel worthy of the support that she received at home. This leads us to conclude that although teachers can do little to influence feedback from family and friends, perhaps it is time we drew PSESLTs' attention to this feedback and gave them the opportunity to talk about it, so that they might perhaps make better use of it and, in turn, help their students make use of the feedback they receive from their own family and friends.

\section{5a. Videotapes of micro-teaching sessions}

From the instructor's point of view, videotaping is a logistical nightmare. In this class, we required five video cameras, five tripods, five extension cords, five master tapes (for the instructor) and 25 individual PSESLT tapes, five electrical outlets (meaning three classrooms), and five individualized lessons on how to use the video cameras. Although many of the PSESLTs found this a valuable form of feedback for self-evaluation, unless a teacher training program is specifically designed to allow for videotaping, or unless the instructor is prepared to reserve, pick up, pay for, haul, and drop off equipment, this form of feedback is unmanageable.

Reactions to the videotaping experience were polarized. The journal entries were marked by candid, often fairly strong language. Whereas one PSESLT wrote, "I especially loved the video" (Journal \#13), another wrote, "I find it rather embarrassing and shut down to some extent" (Journal \#15). Many of the PSESLTs commented that the "videos were a great way of seeing some of the body language you use, both positive and negative things" (Journal \#12), that videos "provided a rare opportunity to see and hear myself as others might. I could actually see myself talking to the blackboard!" (Journal \#11), and that "while I was watching the tape at home ... I was able to catch all that mistakes in my pronunciation, eye-contact, and gesture" (Journal \#13), but other PSESLTs found that these very things increased their nervousness or "added to the apprehensions I have about myself" (Journal \#9). As one PSESLT stated "The videotape of myself does not appeal to me because I am aware of my odd mannerisms but continue to do them anyway" (Journal \#8).

An interesting point about the videotaping (and about audiotaping) is some PSESLTs' aversion to high-tech equipment, which they find "frustrating at the best of times" (Journal \#5). One factor is that the PSESLTs in this 
course tended to be mature, postbaccalaureate, and self-financing. Many had to borrow equipment or use that available in the university library, factors that may have contributed to their dislike of this form of evaluation. Another factor was most PSESLTs' lack of classroom experience. Most practicing ESL teachers deal with audiovisual equipment on a weekly, if not daily, basis, and thereby overcome their reluctance to use it.

\section{5b. Self-evaluation}

Of those PSESLTs who commented on self-evaluation, all found it to be positive. As teachers, we know the benefits of reflecting on our practice and on how theory influences what and how we teach every day. We therefore simply share here two articulate comments:

I have become better able to evaluate my own performance. Self-evaluation is probably most accurate and effective when done immediately after completing an assignment, especially when teaching a lesson. Reflecting on such experiences is useful in that it forces a learner to analyze why something was or was not successful or what she has learned from the experience. It also encourages a learner to take responsibility for her own learning. Putting reflections in writing further facilitates the organization of one's thoughts and can provide a way of seeing the progress that has been made over a period of time. (Journal \#11)

I found the journal writing to be the best learning tool for me and the one that had the greatest effect on my development as a teacher. The journal allowed me to reflect on what I was doing and why with each class and then to see specific ways that I could change the activity to improve it the next time I taught a similar lesson. Journal writing allows the free flow of ideas to be generated without the constraints of formal written text. I found that I produced the most insightful journal entries when it was written spontaneously and when I was able to hand write the ideas that flowed into my head at the time. (Journal \#5)

These comments provide impetus for us to encourage students to reflect and self-analyze, especially informally, during the course of their studies. How to do this without regulating the practice and thus making it less meaningful is the bigger question.

\section{6a. Written response to lesson plans}

The letters from the instructor to individual PSESLTs on their micro-teaching lesson plans were by far the best received. Although this might merely support findings such as those by Belanger and Sloan (1995) that comments received at the beginning of a course term were more favorably regarded than those toward the end, PSESLTs cited some particular reasons for this preference. Many of the PSESLTs felt that they liked to go over the feedback again and again, to "ponder every word" (Journal \#1), and they felt that 
written comments were more amenable to this than oral or visual feedback. Several PSESLTs mentioned that they were visual learners or referred to themselves as poor auditory learners. These PSESLTs said that they had to take notes to retain any kind of oral feedback, so they preferred to have written comments in the first place. Positive comments also ranged from letters being "more private and formal ... more official" (Journal \#3) to "refreshing and very personal" (Journal \#9), and "encouraging ... tailored to the student" (Journal \#4). The writer of Journal \#2 liked this method of feedback because of its indirectness, claiming that "sometimes it is hard for us to talk about negative things face to face. However, this method makes it possible to say such things." On the other hand, the writer of Journal \#13 felt that although the letters were generally positive, the "marks didn't always go along with the contents of the letters." This comment is somewhat confusing because the feedback letters did not assign a mark to the lessons (see description above); perhaps this PSESLT had prior experience with this form of feedback.

On the negative side, a number of PSESLTs mentioned the time delay in producing the letters and the fact that "there is no discussion right away about the student's performance and I feel that the letters somewhat discourage students from pursuing any discussion" (Journal \#3). Indeed, from the point of view of the instructor, I (Kouritzin) would also point to the time delay and lack of discussion. Responding to PSESLT work in letters takes approximately 45 minutes per PSESLT. The instructor must carefully address the PSESLT by name, make recognizable references to the PSESLT's work, and choose words carefully so as not to be too harsh in any negative comment. Because the PSESLTs do not have the benefit of reading the instructor's body language or of clarifying matters for the instructor, and because the letters are written to the PSESLTs as people rather than to their work, even more care than usual must be taken with choice of words and tone. Of the 15 journals only one acknowledged the amount of care and effort that this kind of feedback required, saying this had "obviously taken a great deal more time on the part of the instructor, which made the remarks and suggestions so much more meaningful" (Journal \#4), and approximately one third of the journals made reference to the time delay in receiving this form of feedback.

6b. Instructor audiotaped response to unit plans

Many PSESLTs did not enjoy this form of feedback, although many of those who disliked it also commented that they would use audiotaped feedback in their own teaching practice because they could understand the benefits for ESL students (e.g., that listening to it was an out-of-class listening exercise, or although the PSESLTs were not auditory learners, their students might well be). Those PSESLTs who liked this form of feedback liked being able to hear the expression in the instructor's voice (again pointing to the importance of 
affect), liked the detail, and liked the personal touch that this method of feedback provided. PSESLTs commented:

The instructor's taped evaluation was probably the most comprehensive feedback I have ever received. It provided an immediate and detailed response to every part of my work and gave so much more information than a written commentary could. This was enhanced by being able to hear the tone of the speaker's voice. The taped format also has the advantage over a direct verbal evaluation, of allowing for replays. (Journal \#11)

From my professor's voice, I felt like I was in front of her with the assignment. It was so good feeling to me. Someday, I want to give taped evaluation to my students when I become a teacher. This feedback would be quite powerful to make students have self-esteem. (Journal \#13)

Much is conveyed by the tone, pitch, and volume of voice that cannot be in the printed word. For example, there is much more imparted by a genuinely enthusiastic vocal expression of praise than by an exclamation mark on paper. (Journal \#14)

Because you did this in oral, I was able to feel your warmness, nuance, etc. from your voice. As a result of this, I felt that the relationship between you and me was closer. (Journal \#2)

It is important to note that these or similar comments were often written by PSESLTS who did not receive particularly high grades on their unit plans. It seems that they were able to read friendliness and eagerness to help on the part of the instructor and to gain strength from this.

A particularly interesting comment by one PSESLT points out again that students enjoy feedback that does not contain a grade:

Hearing her expressive voice (with intonation and qualifiers, etc.), and the fact that she used my name, again left me with the impression that it wasn't me being evaluated (causing me to feel defensive) but rather the work. (Journal \#10)

This PSESLT points out that there is a clear distinction in audiotaped feedback between comments directed at the PSESLT's work, and comments, often written in more pointed fashion, directing the PSESLT to do something or suggesting that the PSESLT take something into consideration.

The arguments against this form of feedback are equally compelling. Some PSESLTs did not like feedback that was out of the ordinary and reported that they had difficulty in following it. One PSESLT found that the very factors (being able to hear the pitch, tone, and expression in the instructor's voice) that made some PSESLTs enjoy this form of feedback 
"made me feel vulnerable. I didn't feel I had the power to engage the medium or protect myself against it the way I could with written feedback" (Journal \#7). Many of the PSESLTs mentioned that they listened to the audiotape of the instructor's voice and then wrote her comments onto their lesson plans; they therefore concluded that the audiotape was wasteful. And several PSESLTs felt similar to the writer of Journal \#3:

I found it hard to follow. I had difficulty figuring out what the instructor was referring to even when I listened a second time and had my unit plan in front of me. For something as large as the unit plan, I think that I would rather have had a chance to discuss the project in person. I didn't find the tape to be very effective. It did not motivate me to go back and try to improve the lessons in the unit plan as the other forms of feedback did. Long pauses and background noises made the tape seem informal, hard to hear, and hard to understand. The suggestions did not catch my attention and stick in my mind.

From an instructor's point of view, there is much in these comments to be considered. First, the personal tone and familiarity of the audiotaped responses not only affects the PSESLT, but has an effect on the instructor as well. It is easy to give positive feedback and easy to give balanced feedback in which the instructor can discuss the strengths and the weaknesses of a particular lesson. It is more difficult to give feedback that is primarily negative. It becomes necessary to write notes before commenting onto the tape in order to ensure that words are chosen with care. Moreover, the instructor has to invest a great deal of himself or herself in the comments, while always being aware that this PSESLT may wish to appeal the course mark, at which point the tape-recording of the instructor's voice would be considered "evidence." Finally, this form of feedback is time-consuming; although more information is given, it takes the same amount of time or more to produce as written comments. It may also be difficult to justify to students why audiotaped response is being used rather than face-to-face discussion.

\section{6c. Margin and end notes on formal academic assignments}

Oddly enough, this most common form of feedback in academic classrooms was the only form to receive more negative than positive evaluations, even after a number of PSESLTs commented that they preferred written to oral comments. Reasons for liking this form of feedback included formality and ease of reading, whereas the reasons for not liking it have something important to say to educators.

First, PSESLTs commented that they did not like this form of feedback "because of the 'grade' aspect or the fact that they seem so impersonal" (Journal \#10), which again reminds us that students prefer feedback that is not attached to a grade and that is more personal than generic in tone (see also Belanger \& Sloan, 1995). Second, PSESLTs compared this unfavorably 
with audiotaped feedback, complaining that they "did not get a lot of comments or feedback" (Journal \#2), although the instructor took care to write many comments on each assignment. Finally, many PSESLTs felt this form of feedback was ineffective because, even when they received a good grade, they did not feel that they had received sufficient "guide to show how the evaluator came up with the assigned mark" (Journal \#9). This final comment points to the need for an evaluator to reflect on the assigned criteria for grading a paper and to indicate to the student how the grade was arrived at. From the instructor's point of view, this is a difficult task requiring either that she or he write lengthy comments or also distribute some form of scaled evaluation to accompany the margin and end notes. Although the end comments referred directly to the evaluation criteria, PSESLTs did not feel that they had been adequately informed why they received the grades assigned.

\section{6d. Likert-scale evaluation of book reviews}

We expected the reactions to this form of feedback to be negative because the instructor had explained her own reservations about it, that is, once criteria and their relative weights were established, there was no room for movement. She explained that some well-done assignments were given low grades because they inadequately addressed the criteria, whereas some poorly done assignments received high grades because they met the criteria. She felt that this encouraged the PSESLTs not to take risks or to be innovative and simultaneously robbed the instructor of a feeling of expertise and intuition. She also discussed the meaninglessness of the numbers on a Lickert scale and said it was difficult for her to defend why one person received a 4 and another received a 5 for "maintaining class interest," which was subjectively judged. She suggested that anyone considering using this form of evaluation assign a large number of marks to a category labelled "magic" or "risk-taking and innovation" in order to give room for more subjective marking. Indeed many of the PSESLTs reiterated these comments.

More surprising to us, given the instructor's negative feelings, were the number of PSESLTs who defended this form of evaluation. Even after the instructor's comments about biased marking and the difficulty of applying the rating scale, PSESLT comments abounded similar to this:
I find that I must defend scaled feedback to some extent. Many stu- dents-myself included on occasion-want to know exactly what they did right or wrong. They like things to be broken down in a readily visible fashion. Each mark is accounted for in a more "objective" fashion or there is a more recognizable standard of quality. (Journal \#15)

These kinds of comments perhaps reflect Stiggins' (1991) concern that the current tendency to evaluate process rather than product is not reflected in our marking procedures. Perhaps the instructor's discomfort stemmed from feeling that she was too much focused on evaluating the product rather than 
the process of each individual PSESLT's learning, whereas the PSESLTs felt comfortable being evaluated in terms of the tangible product they produced.

\section{Overall Feedback on Feedback}

An unexpected (and highly gratifying) result was the number of PSESLTs who took the time to comment on how being exposed to various forms of feedback challenged them to think about classroom evaluation. Such comments justify the time spent on this topic. All the responses focused on how exposure to a variety of feedback techniques was important to their learning:

I was thrilled to see a more creative and advantageous approach to evaluation. I will definitely apply the creative evaluation procedures used in this class with my future ESL classes. (Journal \#9)

I feel that the compilation of all the methods of feedback were informative and useful. Variety is the key; it gets you thinking, acting and motivated. (Journal \#1)

Employing a variety of types of feedback, which may include auditory, visual, or written ... may ensure that the greatest number of students are reached. While students may not know best, it would not hurt to inquire of them what type of feedback they find most helpful. (Journal \#15)

These PSESLTs seem to display understanding that not all students react optimally to the same kind of feedback, that they have to ensure variety in order to reach the largest number of students. This is a mark of maturity and growth. These PSESLTs also display an understanding that what the students say they like is not necessarily what will be most effective; that the teacher must attend not only to feedback, but also to results, in order to achieve a good mix of feedback techniques in the classroom.

\section{Summary of Findings}

In short, PSESLTs in this study valued feedback that was immediate such as the feedback they received from peers, from the sponsor teacher, from the instructor as practicum supervisor, and from self-evaluation. Many felt like the PSESLT who wrote:

I consistently found immediate feedback to be much more effective than any form of feedback that I received at a later date. The ideas and considerations are fresh in my mind when I receive immediate feedback and I can respond to the comments made. (Journal \#5)

If feedback could not be immediate, then PSESLTs value a quick response and turn-around time. For the teacher, this is a double-edged sword. Students value good detailed feedback, and they value a quick turn-around 
time, and this is not logistically possible. The 11-22 unpaid hours that the instructor of this course found were required to mark even shorter assignments for a class of 22 PSESLTs (i.e., 30-60 minutes per assignment) may, as Vizard can attest to, be the sum total of a busy ESL instructor's free time for a week!

PSESLTs liked detailed comments and preferred comments to numbers. Most PSESLTs felt that "comments and suggestions were much more important than any actual grades" (Journal \#3). Perhaps because of this, any feedback without grades seemed to be valued highly by the PSESLTs. Given that many of the same PSESLTs also expressed a preference for Likert-scale evaluation, a type of evaluation devoid of comments and suggestions, it seemed that students like either numbers or comments and suggestions rather than a combination of both. We reasoned that perhaps PSESLTs seemed to find comments and suggestions that did not carry grades more egalitarian, whereas Lickert-scale items and numbers were deemed more authoritative.

Finally, PSESLTs seemed to favor factors related to control, both on their own part and on the part of the evaluator. For PSESLTs, control meant being able to affect the feedback process, selecting from a variety of forms, as well as turning it off or tuning it out when they felt unprepared to receive it. For the evaluator, PSESLTs seemed to rely on two components of control: (a) ability to defend the mark given (i.e., the assignment is marked and annotated with reference to some form of articulable control such as the Likert scale used to mark the book review); and (b) authority or credibility (i.e., the evaluator keeps in mind a kind of hypothetical classroom control, suggesting modifications to improve PSESLT performance as a teacher). The instructor's and sponsor teacher's experiences as teachers gave them the necessary preparation to give feedback, whereas their peers taking on the role of students in micro-teaching gave them credibility in giving feedback.

\section{Implications}

First, this study points out the benefits for PSESLTs to consider various forms of feedback during their teacher training. Some of the techniques were new to most PSESLTs. Moreover, discussion of the various forms of feedback, and reflections on them, allowed PSESLTs to think through the decisions they would make about giving feedback in their own classrooms and to consider using forms of feedback that they did not prefer. As one PSESLT commented,

I feel very fortunate to have been exposed to many different kinds of feedback methods during this course. I know that we talked about a variety of forms that feedback might take for our students, but there is no better way to really examine the effectiveness of these forms than to experience them ourselves as students. (Journal \#10) 
Second, because PSESLTs intend to become ESL teachers managing the feedback process in their own classrooms, time should be spent in teacher training programs to talk about the effects of various forms of feedback not just on the those who receive it, but also on the teacher who gives that feedback. ${ }^{9}$ PSESLTs need to know how long it generally takes to mark assignments using different techniques, and they need to discuss time management skills that will enable them to mark assignments adequately and still meet the students' demands for quick turn-around time.

Third, all instructors-preservice, inservice, and teacher trainers-need to know that the feedback relying on margin notes and end notes was not highly appreciated by this group of PSESLTs who wanted to be able to see readily where marks were deducted or gained. Given the prevalence of this form of feedback in academic classrooms, this finding warrants further study, both to pinpoint students' reservations about margin notes and end notes, and with a view to making them more effective. For example, augmenting margin notes and end notes with some form of checklist indicating strengths and weaknesses, as one PSESLT suggested during group discussion, would have helped this group of PSESLTs to see where they gained or lost marks, possibly increasing their satisfaction.

Fourth, given the importance of tone, body language, word choice, and expression, PSESLTs need practice in giving feedback before they go into their own classrooms. They should spend preservice time practicing aspects such as vocal quality, tactful expression of negative feedback, positive body language, comprehensive eye contact, and allowing time for silence before expecting a response.

Fifth, given the positive response to the research process in this course, PSESLTs should be invited to give feedback on feedback in their preservice classrooms so that they can develop this knowledge through experience, self-reflection, and discovery.

Finally, there is a need for a good teaching textbook about feedback, delineating the various forms of feedback, discussing the strengths and weaknesses of each, posing case study examples, and giving plentiful examples of appropriate word choice in writing, speaking, or otherwise conveying feedback.

\footnotetext{
Notes

${ }^{\mathrm{l}}$ We would like to note, however, that a number of progressive universities and colleges are beginning to institute credit ESL courses, usually academic preparation courses, that are given summative evaluations.

${ }^{2}$ In this section, the course instructor and practicum supervisor were the same person, which is not the usual case. For ease of reference, course instructor means both roles.

${ }^{3}$ The lesson plans themselves were not graded because some of the students had teaching experience and others did not. The grades for the micro-teaching lesson plans were therefore based on the quality of individual student learning as demonstrated by their reflections.
} 
${ }^{4}$ The list itemized on the course syllabus listed the criteria as: (a) the appropriateness of the unit rationale and objectives given the situation and circumstances you describe; (b) the continuity and coherence of the lessons you have selected; (c) the usefulness of the activities or lessons you have selected; (d) the opportunities created for meaningful interaction and communication among students and with the teacher; (e) the appropriateness of feedback and evaluation strategies; $(\mathrm{f})$ the organization and presentation of the unit plan; $(\mathrm{g})$ the potential for the unit plan to help students develop intrinsic motivation; $(h)$ the opportunities for intensive practice of language forms; (i) skills are spiraled so that they are practiced in many contexts; (j) the four skills are represented and are integrated; $(\mathrm{k})$ material is introduced in a variety of ways to accommodate a variety of learning styles; and (l) balanced and effective use of techniques and media.

${ }^{5}$ Ideally, this checklist would have been formulated by the class, but because the course syllabus was written before our class decision to engage in this research, it was based on established criteria. Those criteria were roughly (a) stimulation of interest, (b) adherence to time and space restrictions, (c) ability to critique in terms of the ideas presented in the course, and (d) organization and presentation.

${ }^{6}$ Although 22 students were enrolled in the course, six did not complete the course requirements within the allotted time, and Vizard's journal was not included in the study.

${ }^{7}$ One journal of the 15 needs to be discounted in this study because the PSELST made only oblique references to most forms of feedback, instead grading the instructor on her teaching ability and style. This journal accounts for most of the nonapplicable comments tallied in Table 1.

${ }^{8}$ On reflection, I (Kouritzin) realize that this was a serious omission from my course outline. In future, I plan to address specifically understanding and incorporating feedback from students in practicum classrooms in this course. I should have told my students what to look for in terms of body language, eye contact, and other affective factors, as well as offering them suggestions and ideas for how to elicit feedback from their students on an ongoing basis.

${ }^{9}$ Moreover, in an age of accountability, there are legal ramifications every time an instructor gives feedback. PSESLTs also must be aware that certain forms of feedback, such as audiotaped responses and written letters, invite students to have a more intimate relationship with instructors.

\section{Acknowledgments}

Earlier versions of this article were presented at the 1998 Annual Meeting of the Canadian Society for the Study of Education, Ottawa and the 1999 Annual TESOL Convention in New York.

The authors would like to thank Pat Mathews and two anonymous TESL Canada Journal reviewers for their helpful suggestions and insights.

\section{The Authors}

Sandra Kouritzin is an assistant professor of TESL in the Department of Curriculum, Teaching and Learning at the University of Manitoba in Winnipeg, MB. Her dissertation research (UBC, 1997) and postdoctoral research (SSHRC, OISE/UT) is primarily concerned with first language loss (Facelt ls of First Language Loss, 1999). She can be reached at: kouritzi@ms.umanitoba.ca

Carol Vizard began teaching at the junior high school level in Ontario. During a six-year stay in Italy, she worked in the field of EFL English where her responsibilities included teaching students of all ages and levels, developing curriculum, and designing original materials for classroom use. For the past six years Carol has been teaching ESL English (elementary to Cambridge proficiency) in Vancouver, BC. 


\section{References}

Bachman, L.F. (1991). What does language testing have to offer? TESOL Quarterly, 25, 671-704.

Belanger, J., \& Sloan, A. (1995). Memo re: Research project to observe students' responses to their teachers' comments on written compositions. Unpublished manuscript, University of British Columbia.

Boswood, T., \& Dwyer, R.H. (1995/6). From marking to feedback: Audiotaped response to student writing. TESOL Journal, 5, 20-23.

Charles, M. (1990). Responding to problems in written English using a student self-monitoring technique. ELT Journal, 44, 286-293.

Connor-Linton, J. (1995). Looking behind the curtain: What do L2 composition ratings really mean? TESOL Quarterly, 29, 762-765.

Ferris, D.R. (1995). Student reactions to teacher response in multiple-draft composition classrooms. TESOL Quarterly, 29, 33-54.

Ferris, D.R. (1997). The influence of teacher commentary on student revision. TESOL Quarterly, $31,315-340$.

Hedgcock, J., \& Lefkowitz, N. (1994). Feedback on feedback: Assessing learner receptivity to teacher response in L2 composing. Journal of Second Language Writing, 3, 141-163.

Hyland, K. (1990). Providing productive feedback. ELT Journal, 44, 279-285.

Leki, I. (1990). The preferences of ESL students for error correction in college-level writing classes. Foreign Language Annals, 24, 203-218.

Machell, J. (1995). The teacher evaluation environment: An examination of attributes related to teacher growth. Journal of Personnel Evaluation in Education, 9, 259-73.

Robb, T., Ross, S., \& Shortreed, I. (1986). Salience of feedback on error and its effect on EFL writing quality. TESOL Quarterly, 20, 83-93.

Saito, H. (1994). Teachers' practices and students' preferences for feedback on second language writing: A case study of adult ESL learners. TESL Canada Journal, 11, 46-70.

Shohamy, E. (1993). The power of tests: The impact of language tests on teaching and learning. NFLC Occasional Papers, 1-19.

Spolsky, B. (1995). Measured words. Oxford: Oxford University press.

Stiggins, R. (1991). Relevant classroom assessment training for teachers. Educational Measurement: Issues and Practice, 10, 7-12.

Sweeney, J. (1992). The effects of evaluator training on teacher evaluation. Journal of Personnel Evaluation in Education, 6, 7-14. 